\title{
THE EARLY RECOGNITION OF DIABETES MELLITUS*
}

\author{
Stefan S. Fajans and Jerome W. Conn \\ Division of Endocrinology and Melabolism, Depariment of Internal Medicine, \\ University of Michigan Medical School, Ann Arbor, Mich.
}

Progressively earlier recognition of the diabetic state is vital if progress is to be made toward the eventual control and prevention of the disease. The presence of mild diabetes mellitus may remain unrecognized in a large number of individuals for many years unless diagnostic laboratory procedures are freely employed in groups of individuals in whom experience has shown a high incidence of latent diabetes. Dependable diagnostic criteria are now available that make it possible to detect these previously unsuspected diabetic individuals. In addition, it is hoped that other means for detection of the diabetic state will be discovered that will give earlier evidence of its existence than is possible by present methods of testing.

This discussion has two purposes, first, to consider the use and the criteria for the interpretation of the standard oral glucose tolerance test employed for the early detection of diabetes and second, to consider experience with the cortisone-glucose tolerance test as used for the possible prediction of future diabetes mellitus.

The early recognition of diabetes mellitus depends upon the use and interpretation of proper laboratory procedures. In some cases the presence of latent diabetes will be recognized by routine performance of urinalysis and the determination of a single blood sugar level. In the mildest forms of the disease these procedures may be of little aid. In these cases the earliest recognizable abnormality may be a diminished ability to utilize a carbohydrate load as demonstrated by a glucose tolerance test.

We have used the oral glucose tolerance test in our studies. For at least 3 days preceding the test the subjects ingest a diet containing approximately $300 \mathrm{gm}$. carbohydrate per day plus maintenance calories. ${ }^{1}$ Although the ingestion of smaller amounts of carbohydrate is sufficient to prevent abnormal tests in normal subjects, a standardized high-carbohydrate preparatory diet is advised to ensure the reproducibility of the test. The loading dose of glucose used is $1.75 \mathrm{gm} . / \mathrm{kg}$. of ideal body weight. Blood sugar levels are determined in venous blood by the Somogyi-Nelson technique.

The criteria that we employ for the interpretation of the standard oral glucose tolerance test are illustrated in FIGURE 1.2 Carbohydrate tolerance is considered to be normal when the peak blood sugar value is less than $160 \mathrm{mg}$./ $100 \mathrm{ml}$. and the 2-hour value is less than $110 \mathrm{mg} . / 100 \mathrm{ml}$. We regard the combination of an 1 -hour value of $160 \mathrm{mg}$. $/ 100 \mathrm{ml}$. or above plus a 2 -hour value of $120 \mathrm{mg} . / 100 \mathrm{ml}$. or above as diagnostic of the existence of the diabetic state. In borderline curves the level at $1 \frac{1}{2}$ hours is required to be $140 \mathrm{mg} . / 100 \mathrm{ml}$. or above to be diagnostic. This restriction eliminates a false diagnosis of

* The work reported in this paper was supported in part by Research Grant A-888 from the National Institute of Arthritis and Metabolic Diseases, Public Health Service, Bethesda, Md. 
diabetes on the occasional curve that drops abruptly to normal at $11 / 2$ hours and then rebounds above $120 \mathrm{mg}$. $/ 100 \mathrm{ml}$. by 2 hours. FIGURE 1 shows that a diabetic curve is one in which all points lie at or above the upper border of the shaded triangle. A diagnosis of "probable diabetes" is made when the 1-hour value is $160 \mathrm{mg}$./100 ml. or above, the $11 / 2$-hour value $135 \mathrm{mg}$. $/ 100 \mathrm{ml}$. or above, and the 2-hour value is between 110 and $120 \mathrm{mg}$. $/ 100 \mathrm{ml}$., which falls within the shaded zone of FIGURE 1. It should be emphasized that these criteria for the interpretation of the glucose tolerance test are applicable only in ambulatory and otherwise healthy individuals.

The criteria described are similar to those of Moyer and Womack ${ }^{3}$ and those

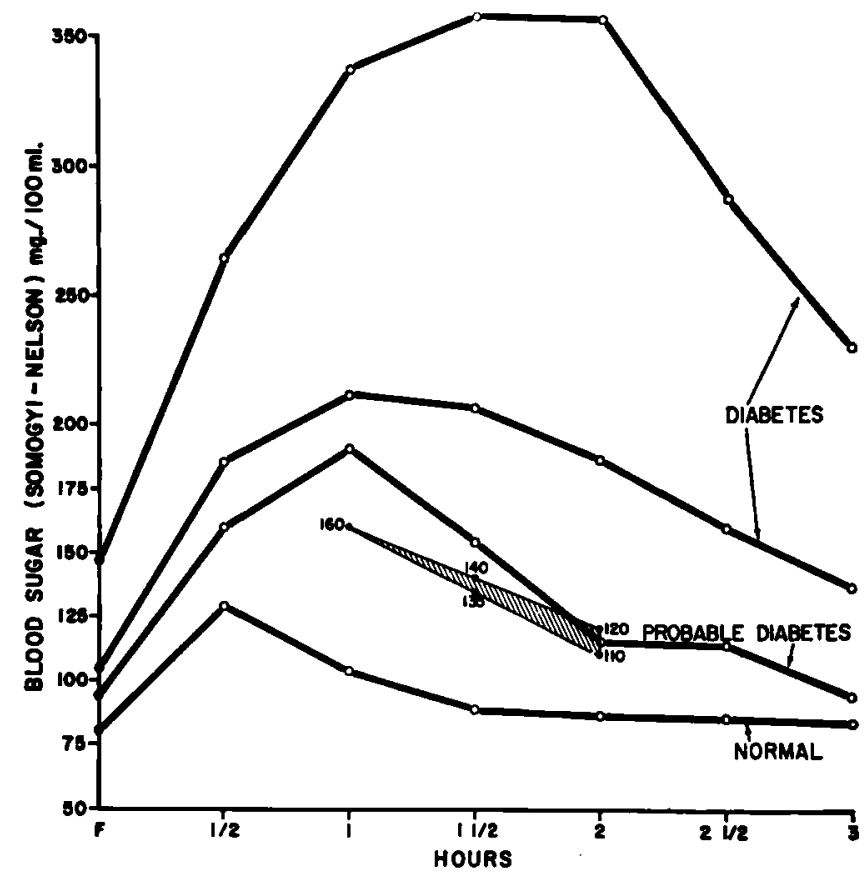

Figure 1. Criteria used for the interpretation of the standard oral glucose tolerance test.

of Mosenthal and Barry. However, our criteria are less restrictive than those of Mosenthal and Barry, who considered carbohydrate tolerance to be abnormal when the maximum blood sugar value is above $150 \mathrm{mg}$. $/ 100 \mathrm{ml}$. and the 2-hour value above $100 \mathrm{mg} . / 100 \mathrm{ml}$. Also, these workers did not employ a value at $11 / 2$ hours in mildly abnormal glucose tolerance tests to eliminate false positive rebound curves.

It is obvious that any criteria which employ a sharp dividing line between normal and abnormal must be arbitrary. What, then, are the justifications that make us believe that our criteria are sound? Applying these criteria in 127 healthy subjects without a history of familial diabetes or large babies, we have found only one glucose tolerance test indicating diabetes and one indicating "probable diabetes." In addition, careful follow-up of patients with mild 
abnormalities of glucose tolerance frequently shows further impairment of carbohydrate utilization clearly diagnostic of diabetes mellitus. Decompensation of carbohydrate tolerance may occur rapidly, although in middle-aged individuals loss of glucose tolerance may be only slowly progressive over many years. The following examples will serve to illustrate the significance of mild abnormalities of giucose tolerance as defined by our criteria.

Subject A. N. (TABIE 1) shows a 1-hour blood sugar value of $177 \mathrm{mg} . / 100$ $\mathrm{ml}$. and a 2-hour value of $121 \mathrm{mg} . / 100 \mathrm{ml}$. A few days later, fasting hyperglycemia was diagnostic of diabetes mellitus. Patient K. C. (TABLE 2) is an example of "probable diabetes," since the 2-hour value is between 100 and 120/ $\mathrm{mg} . / 100 \mathrm{ml}$. Nine years later no doubt remains about the diagnosis of dia-

TABLE 1

Patient A. N., Male, Aged 69 Years, Height 5'8", Weight 160 lb.

\begin{tabular}{l|r|c|c|c|c|c}
\hline \multirow{2}{*}{ Date } & \multicolumn{5}{|c}{ Glucose tolerance test (hours) } \\
\cline { 2 - 5 } & Fasting & 13 & 1 & 136 & 2 & 3 \\
\hline $\begin{array}{l}9-14-58 \\
9-17-58 \text { (surgery) }\end{array}$ & $\begin{array}{r}94 \\
124 \\
171\end{array}$ & 171 & 177 & 188 & 121 & 143 \\
\hline \hline
\end{tabular}

TABLE 2

Patient K. C., Male, Height 6'1", Family History of Diabetes (Mother)

\begin{tabular}{|c|c|c|c|c|c|c|c|c|c|c|c|c|}
\hline \multirow{2}{*}{ Year } & \multirow{2}{*}{ Age } & \multirow{2}{*}{ Weight } & \multicolumn{10}{|c|}{ Glucose tolerance test (hours) } \\
\hline & & & Fasting & $1 / 2$ & 1 & $13 / 2$ & 2 . & 236 & 3 & $31 / 2$ & 4 & $41 / 2$ \\
\hline $\begin{array}{l}1948 \\
1957\end{array}$ & $\begin{array}{l}36 \\
45\end{array}$ & $\begin{array}{l}160 \\
183\end{array}$ & $\begin{array}{r}76 \\
119 \\
115\end{array}$ & & 197 & & 118 & 96 & 54 & 36 & 58 & 68 \\
\hline 1958 & 46 & 191 & $\begin{array}{r}100 \\
96\end{array}$ & $\begin{array}{r}208 \\
177\end{array}$ & $\begin{array}{l}286 \\
216\end{array}$ & 260 & $\begin{array}{r}216 \\
288\end{array}$ & $\begin{array}{l}\text { (Diet } \\
\text { aft }\end{array}$ & $\begin{array}{l}\text { liscon } \\
3 \text { m } \\
179\end{array}$ & $\begin{array}{l}\text { ued } \\
\text { hs) }\end{array}$ & pat & \\
\hline
\end{tabular}

betes mellitus. In subject A. C. (TABLE 3) the diagnosis of probable diabetes could have been made in 1934 . Nineteen years later he developed symptoms of frank diabetes, and diagnostic fasting hyperglycemia was found.

The last 2 patients exhibited another manifestation of early diabetes mellitus. Terminal hypoglycemia 3 to 5 hours after ingestion of glucose occurs in a large number of individuals whose glucose tolerance tests disclose mild diabetes mellitus. ${ }^{5}$ Occurrence of terminal hypoglycemia does not rule out the presence of diabetes mellitus. Symptoms of spontaneous hypoglycemia 3 to 5 hours after meals occur in many cases with early mild diabetes mellitus, and may indeed be one of the earliest clinical manifestations of the disease. Of a series of 110 patients with glucose tolerance tests that exhibited early hyperglycemia and late hypoglycemia, 44 per cent had a family history of diabetes mellitus. $^{5}$ 
Several types of glucose tolerance curves that cannot be classified as indicating diabetes or probably diabetes according to our criteria, but which nevertheless may have prognostic significance, deserve comment. The diagnosis of diabetes mellitus cannot be made with confidence on the basis of an abnormal elevation of the blood sugar level at $1 / 2$ or 1 hour if it is accompanied by a normal 2-hour blood sugar level during the glucose tolerance test. Rapid transit of

TABLE 3

Patient A. C., Male, Height 6'0", Glycosuria Found Twice in 1930

\begin{tabular}{|c|c|c|c|c|c|c|}
\hline \multirow{2}{*}{ Year } & \multirow{2}{*}{ Age } & \multirow{2}{*}{ Weight } & \multicolumn{4}{|c|}{ Glucose tolerance test (hours) } \\
\hline & & & Fasting & 1 & 2 & 3 \\
\hline $\begin{array}{c}1934 \\
1953 \\
11-17-53 \\
12-10-53\end{array}$ & $\begin{array}{l}48 \\
67\end{array}$ & $\begin{array}{l}170 \\
182\end{array}$ & $\begin{array}{c}0 \\
86 \\
\text { Polyuria, } \\
\text { during } \\
++++ \\
220 \\
++++ \\
232\end{array}$ & \begin{tabular}{|c|}
+ \\
205 \\
polydipsea, \\
preceding mo
\end{tabular} & $\begin{array}{c}+++ \\
115 \\
7 \text {-pound } \\
\text { onth }\end{array}$ & $\left.\right|_{\text {weight loss }} ^{++}$ \\
\hline
\end{tabular}

TABLE 4

Prognostic Importance of Abnormally High Peak Blood Sugar Levels With Normal 2-Hour LeVels

\begin{tabular}{|c|c|c|c|c|c|c|c|c|c|c|}
\hline \multirow{2}{*}{ Subject and height } & \multirow{2}{*}{ Date } & \multirow{2}{*}{ Age } & \multirow{2}{*}{ 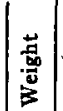 } & \multicolumn{7}{|c|}{ Glucose tolerance test (hours) } \\
\hline & & & & Fasting & $1 / 2$ & 1 & $11 / 2$ & 2 & $21 / 2$ & 3 \\
\hline M. P., male, $6^{\prime}$ & $\begin{array}{l}1935 \\
1940\end{array}$ & $\begin{array}{l}43 \\
48\end{array}$ & $\begin{array}{l}160 \\
161\end{array}$ & $\begin{array}{c}0 \\
130 \\
+++ \\
211\end{array}$ & & $\underset{174}{++}+$ & & $++\underset{93}{+}+$ & & $\begin{array}{c}0 \\
68\end{array}$ \\
\hline A. M., female, $5^{\prime} 5^{\prime \prime}$ & $\left|\begin{array}{r}3-5-53 \\
6-25-53 \\
3-23-59\end{array}\right|$ & $\begin{array}{l}33 \\
33 \\
39\end{array}$ & $\begin{array}{l}160 \\
162 \\
148\end{array}$ & $\begin{array}{c}0 \\
100 \\
123 \\
136\end{array}$ & $\begin{array}{l}214 \\
240\end{array}$ & $\begin{array}{l}++ \\
180 \\
259 \\
280\end{array}$ & $\begin{array}{l}189 \\
264\end{array}$ & $\begin{array}{r}+ \\
96 \\
158 \\
180\end{array}$ & $\begin{array}{l}163 \\
193\end{array}$ & $\begin{array}{l}+ \\
118 \\
137 \\
137\end{array}$ \\
\hline J. G., male, $5^{\prime} 10^{\prime \prime}$ & $\left|\begin{array}{r}3-15-55 \\
6-1-55\end{array}\right|$ & $\begin{array}{l}24 \\
24\end{array}$ & $\begin{array}{l}178 \\
177\end{array} \mid$ & $\begin{array}{c}0 \\
98 \\
0 \\
88\end{array}$ & $\begin{array}{c}+++ \\
198 \\
188\end{array}$ & $\begin{array}{c}+++ \\
153 \\
+++ \\
207\end{array}$ & $+{ }_{214}^{++}$ & $\begin{array}{c}+++ \\
+76 \\
++ \\
218\end{array}$ & 143 & $\begin{array}{c}0 \\
56 \\
+++ \\
140\end{array}$ \\
\hline
\end{tabular}

glucose through the pylorus may give rise to abnormally rapid intestinal absorption of glucose and to high peak blood sugar values. However, careful follow-up of otherwise healthy individuals with abnormally high peak blood sugar levels during the glucose tolerance test is indicated. TABLE 4 shows the progression of such curves to curves diagnostic of diabetes mellitus.

Renal, or nondiabetic, glycosuria has been thought to be a benign condition. A majority of authors have reported the development of diabetes in such individuals to be no more frequent than in the general population. However, 
we have found unsuspected diabetes in 63 per cent of the patients with nondiabetic glycosuria in whom follow-up glucose tolerance tests were performed up to 30 years later. ${ }^{6}$ Approximately one third of the group had initially exhibited fasting glycosuria. This fact indicates that nondiabetic, or renal, glycosuria may be indicative of potential diabetes, and that such patients should be retested periodically for the presence of diabetes mellitus. TABLE 5 shows examples of the transition from nondiabetic glycosuria to diabetes mellitus.

Mild variations of glucose tolerance may be encountered when the test is repeated at intervals of more than a few days in the same individual. In general, however, there is a high degree of reproducibility when the oral glucose tolerance test is carefully performed in conjunction with the use of a standard high-carbohydrate preparatory diet and a true blood sugar method. Occasionally one encounters a rapid change from an abnormal glucose tolerance test to a normal one. It has been recognized for many years that reduction of body weight in the obese middle-aged diabetic patient may result in a

TABLE 5

Transition from Nondiabetic Glycosuria to Diabetes Mellitus

\begin{tabular}{|c|c|c|c|c|c|c|c|c|c|c|}
\hline \multirow{2}{*}{ Subject and height } & \multirow{2}{*}{ Year } & \multirow{2}{*}{ Age } & \multirow{2}{*}{ 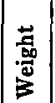 } & \multicolumn{7}{|c|}{ Glucose tolerance test (hours) } \\
\hline & & & & Fasting & 3/2 & 1 & $11 / 2$ & 2 & $21 / 2$ & 3 \\
\hline A.B., female, & $\begin{array}{l}1936 \\
1948\end{array}$ & $\begin{array}{l}22 \\
34\end{array}$ & $\begin{array}{l}114 \\
115\end{array}$ & $\begin{array}{c}0 \\
89 \\
++++ \\
260\end{array}$ & (Polyur & $\mid \begin{array}{c}++t \\
135 \\
\text { ia, polydi }\end{array}$ & $\left.\right|_{\text {psea, weig }}$ & $\begin{array}{c}++ \\
104 \\
\text { ht loss })\end{array}$ & & $\begin{array}{l}0 \\
64\end{array}$ \\
\hline F. J., male, $6^{\prime} 0^{\prime \prime}$ & $\begin{array}{l}1937 \\
1956\end{array}$ & $\begin{array}{l}48 \\
67\end{array}$ & $\begin{array}{l}190 \\
190\end{array}$ & $\begin{array}{l}++ \\
97 \\
++ \\
97\end{array}$ & $+\underset{188}{++}+$ & $\underset{107}{+++}+\underset{186}{++}$ & $+\underset{151}{t+}+$ & $\begin{array}{c}++ \\
91 \\
+++ \\
136\end{array}$ & $+\underset{127}{+}+$ & $\begin{array}{c}++ \\
68 \\
+++ \\
102\end{array}$ \\
\hline
\end{tabular}

return to normal of the glucose tolerance test. ${ }^{7}$ It is less well recognized that spontaneous reversal of an abnormal glucose tolerance test to normal may also occur in young untreated diabetics; thus, a change from a glucose tolerance test diagnostic of diabetes, by the criteria given, to a normal one does not invalidate these criteria per se. An extreme example of such a change to a nondiagnostic glucose tolerance test with subsequent development of severe diabetes with complications is shown in TABLE 6 .

Having discussed the criteria for the interpretation of the oral glucose tolerance test and the significance of mild abnormalities of carbohydrate tolerance, we indicate one use of this test as it applies to the early detection of diabetes mellitus. Figure 2 shows the results of the standard glucose tolerance test when performed in 438 close relatives (parents, siblings, or children) of known diabetic patients. Of this group, 340 (77 per cent) had normal glucose tolerance curves. Curve 1 is the composite curve of this group. Of the 438, 81 (19 per cent) were found to be diabetic. Curve 2 is the composite curve for these previously unsuspected diabetics. Seventeen of the 438 relatives, (4 per cent) gave curves indicating probable diabetes (curve 3 ). In contrast, 
using the same criteria in a control group of 127 subjects without a family history of diabetes or of large babies, only one previously unrecognized diabetic (Curve 2) and one probable diabetic (Curve 3) were discovered. The other 125 subjects, (more than 98 per cent) had normal glucose tolerance tests. Thus, at least a 19 per cent incidence of previously unsuspected diabetes can be found

TABLE 6

Reversibility of Diagnostic Glucose Tolerance Test

B. S., male: height $5^{\prime} 6^{\prime \prime}$, weight $152 \mathrm{lb}$.

3-16-38 Glucosuria found, but no symptoms

\begin{tabular}{|c|c|c|c|c|c|}
\hline \multirow{2}{*}{ Date } & \multirow{2}{*}{ Age } & \multicolumn{4}{|c|}{ Glucose tolerance test (hours) } \\
\hline & & Fasting & 1 & 2 & 3 \\
\hline $3-18-38$ & 24 & $\begin{array}{c}0 \\
214 \\
0\end{array}$ & 375 & 353 & 273 \\
\hline $3-29-38$ & 24 & 107 & 146 & 112 & 99 \\
\hline 1946 & 32 & \multicolumn{4}{|c|}{$\begin{array}{l}\text { Furunculosis, polydipsea, polyphagia, 8-lb. weight } \\
\text { loss; recovered without treatment. }\end{array}$} \\
\hline 1947 & 33 & \multicolumn{4}{|c|}{$\begin{array}{l}\text { Abdominal wall abcess, fatigue: } F B S-350 \mathrm{mg} . / \\
100 \mathrm{ml} \text {. Diagnosis: Diabetes mellitus. Diet } \\
\text { and insulin. }\end{array}$} \\
\hline 1948 & 34 & \multicolumn{4}{|c|}{ Retinitis proliferans, vitreous hemorrhages. } \\
\hline
\end{tabular}
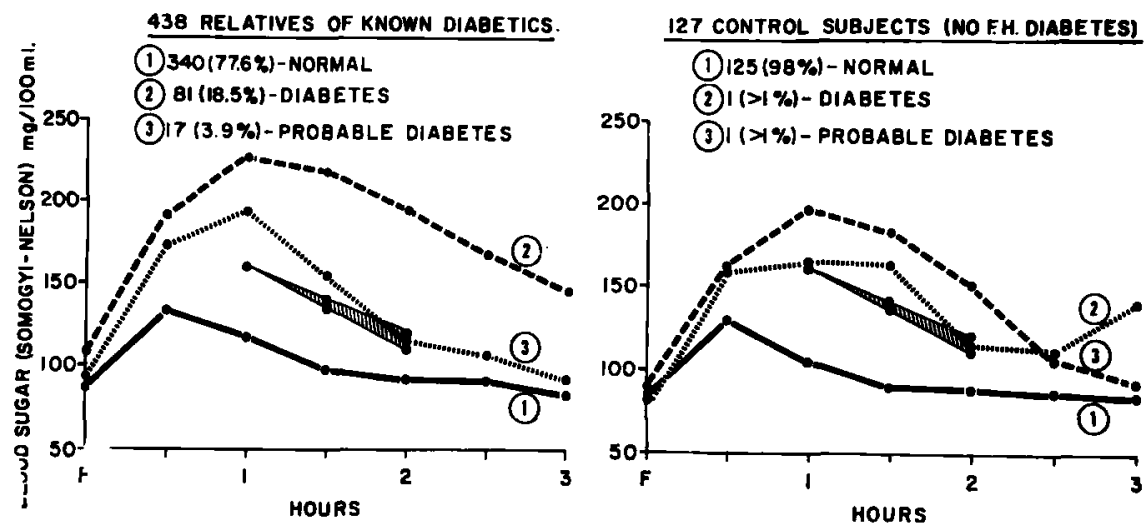

Figure 2. Standard oral glucose tolerance tests.

in close relatives of diabetic patients, while this incidence is less than 1 per cent in the control group. A very much higher incidence of previously unrecognized diabetes will be found if studies are conducted among close relatives of diabetic patients than in the general population.

To develop means of recognizing the potential diabetic is the aim of our current investigations. The cortisone-glucose tolerance test has been used as a test for determining the potentiality for the development of the disease. 
When this test is applied to nondiabetic relatives of diabetic patients it may serve as a means for predicting future diabetes. ${ }^{2,8, ~} 8$

We used the following technique for the performance of the cortisone-glucose tolerance test in our studies. An individual weighing less than $160 \mathrm{lb}$. receives orally $50 \mathrm{mg}$. of cortisone acetate $81 / 2$ hours and again 2 hours before the ingestion of glucose. If body weight exceeds $160 \mathrm{lb} ., 62 \frac{1}{2} \mathrm{mg}$ cortisone acetate is given orally at the same time intervals. A value of $140 \mathrm{mg}$. per cent at 2 hours is the critical level for interpretation of the cortisone-glucose tolerance test. Thus, a cortisone-glucose tolerance test giving a 2-hour blood sugar level of $140 \mathrm{mg}$. per cent or above (and therefore lying at or above the line connecting the points of $160 \mathrm{mg}$. per cent at 1 hour and $140 \mathrm{mg}$. per cent at 2 hours in FIGURE 3), represents a "positive response," while a curve with a level of below $140 \mathrm{mg}$. per cent at 2 hours is regarded as a "negative response."

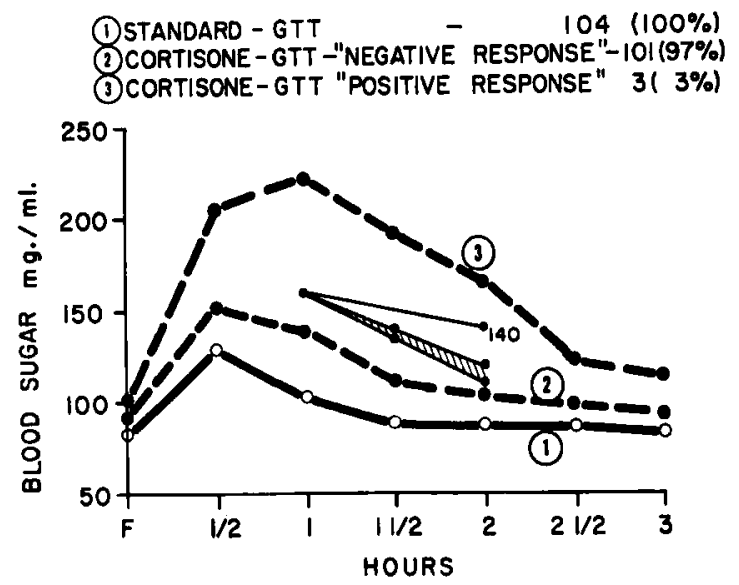

Figure 3. Cortisone-glucose tolerance tests on 104 healthy subjects with no family history of diabetes or large babies.

Figure 3 illustrates our findings with the cortisone-glucose tolerance test in a group of 104 control subjects without a family history of diabetes or large babies. Curve 1 demonstrates their composite standard glucose tolerance test before cortisone was given. After administration of cortisone 101 subjects or 97 per cent of the control group gave "negative responses" to this test with a mean 2-hour blood sugar of $104 \mathrm{mg} . / 100 \mathrm{ml}$. (Curve 2). Three subjects ( 3 per cent) of the group gave a "positive response" to this test.

Cortisone-glucose tolerance tests were performed in 295 nondiabetic relatives of known diabetics. All of these subjects had normal control glucose tolerance tests as shown in Figure 4. After administration of cortisone 220 of the 295 individuals ( 75 per cent) showed a negative response with a mean 2-hour blood sugar level of $106 \mathrm{mg}$. per cent, a response seen in 97 per cent of the control group. Seventy-five of the 295 subjects (25 per cent) showed a positive response. Thus, 25 per cent of the group of nondiabetic relatives respond to this test as do only 3 per cent of the control group.

FIGURE 5 shows the data obtained with 17 subjects classified by their initial 
glucose tolerance test as individuals with probable diabetes (Curve 1). Fifteen of the 17 (88 per cent) gave positive responses to the cortisone-glucose tolerance test, while 2 of the 17 gave negative responses to it.

Figure 6 demonstrates data obtained in 22 obese, mild diabetic patients. Curve 1 shows the composite glucose tolerance test before reduction of body weight. After weight reduction all subjects exhibited normal standard glucose tolerance curves, as shown in Curve 2. Cortisone-glucose tolerance tests
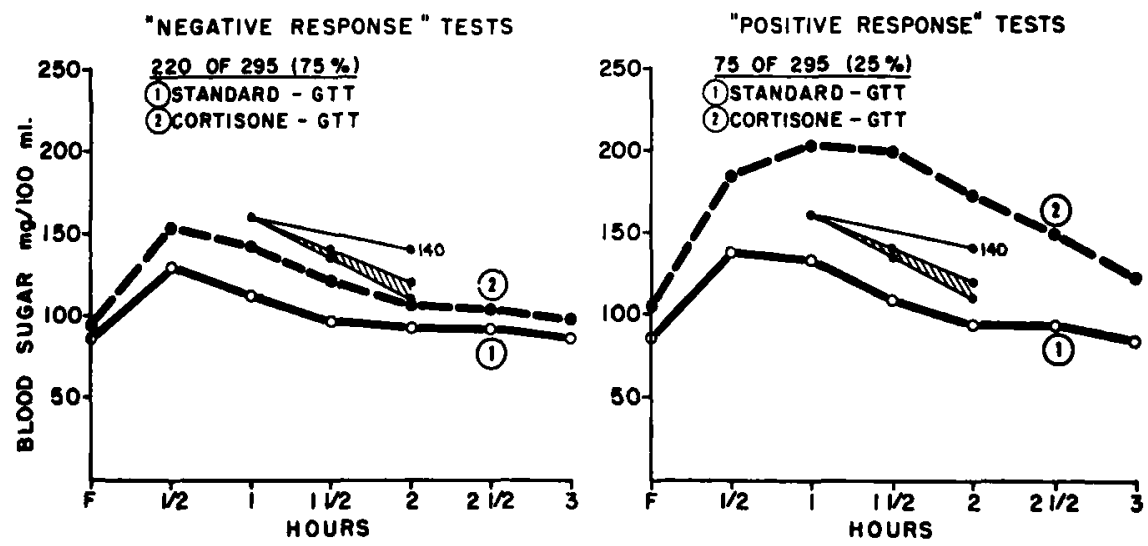

Figure 4. Cortisone-glucose tolerance tests on 295 nondiabetic relatives of diabetic patients.
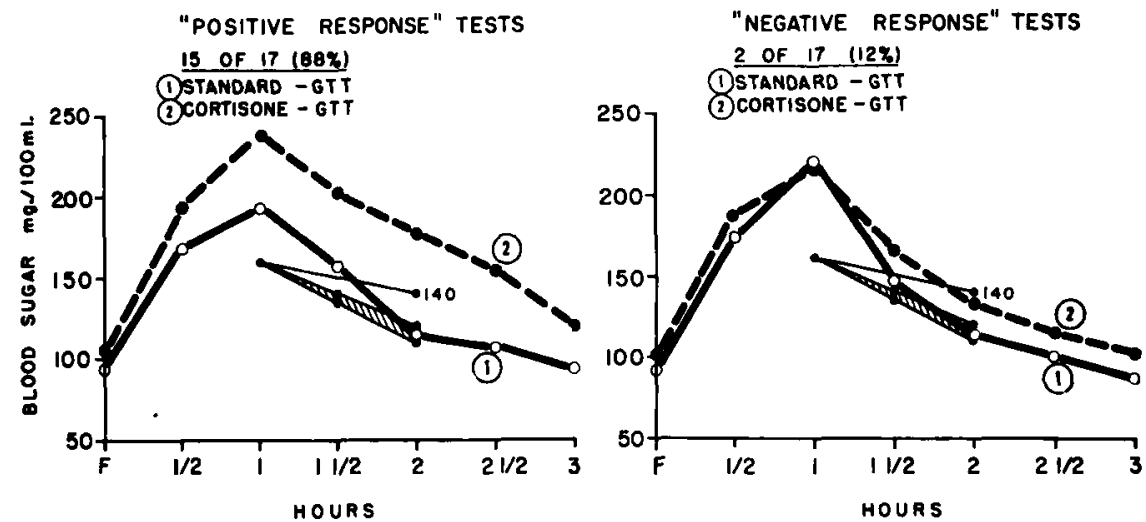

Figure 5. Cortisone-glucose tolerance tests on 17 subjects with probable diabetes.

were then performed. Of the 22,19 ( 86 per cent) gave a positive response to the test (Curve 3).

In correlating these results it seems very significant that 25 per cent of the group of nondiabetic relatives of diabetic patients respond to this test in the same way as do 88 per cent of patients with probable diabetes and 86 per cent of the group of obese diabetics whose carbohydrate tolerance had returned to normal after reduction of body weight. On the other hand, only 3 per cent of the control group without a family history of diabetes gave a positive response to the cortisone-glucose tolerance test. 
(1) STANDARD - GTT BEFORE WEIGHT LOSS

(3) STANDARD - GTT AFTER WEIGHT LOSS

(3)CORTISONE-GTT AFTER WEIGHT LOSS
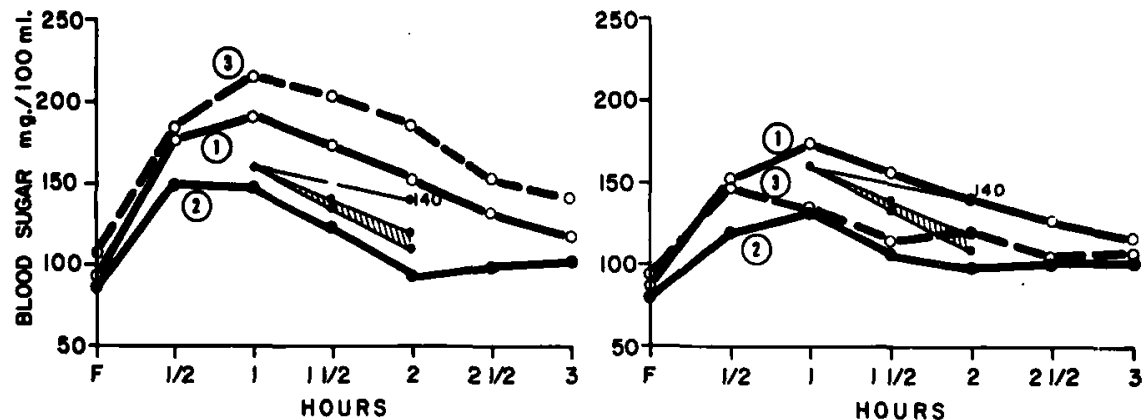

Figure 6. Cortisone-glucose tolerance tests on 22 obese diabetic subjects after loss of body weight.

TABLE 7

Follow-Up (1 to 6 Years) Results in 91 Nondiabetic Relatives of Diabetic Patients

\begin{tabular}{|c|c|c|c|c|}
\hline \multicolumn{2}{|c|}{ Initial normal GTT } & \multicolumn{3}{|c|}{ Progression to: } \\
\hline Cortisone-GTT & Number subjects & $\begin{array}{l}\text { Diabetes } \\
\text { number }\end{array}$ & $\begin{array}{l}\text { Probable } \\
\text { diabetes } \\
\text { number }\end{array}$ & $\begin{array}{c}\text { Total } \\
\text { abnormal } \\
\text { number }\end{array}$ \\
\hline $\begin{array}{l}\text { Positive response . . . } \\
\text { Negative response. . . }\end{array}$ & $\begin{array}{l}\mathbf{3 4} \\
\mathbf{5 7}\end{array}$ & $\begin{array}{l}6(18 \%) \\
1(2 \%)\end{array}$ & $4 \underset{0}{(12 \%)}$ & $\begin{aligned} 10 & (30 \%) \\
1 & (2 \%)\end{aligned}$ \\
\hline
\end{tabular}

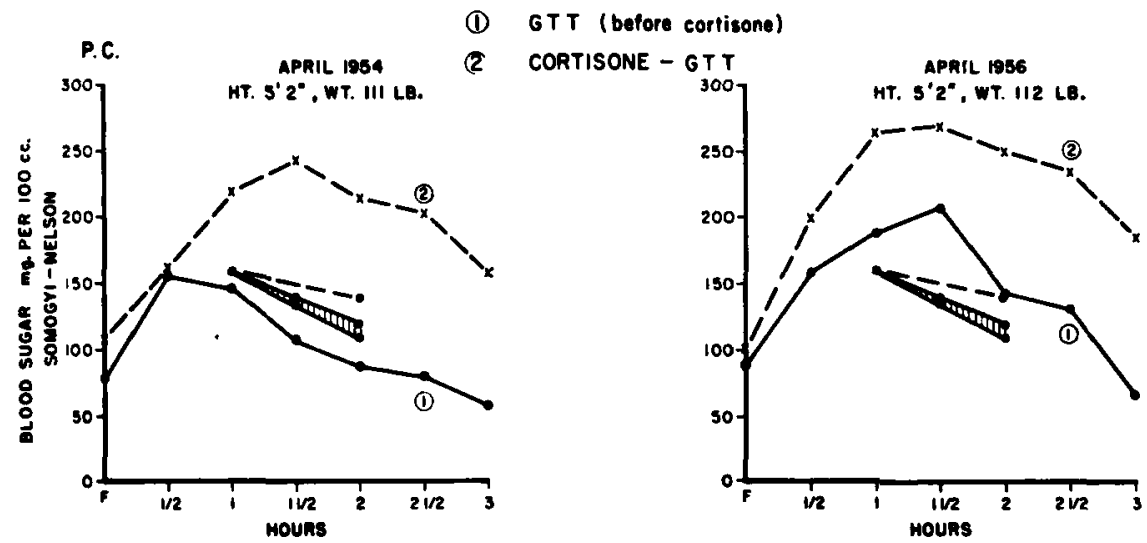

FIGURE 7. Glucose tolerance tests and cortisone-glucose tolerance tests in a 32-year-old female patient with familial diabetes mellitus (father and brother). 
Thus, using this test the presently nondiabetic relatives of diabetic patients can be divided into two groups: "Positive response" and "negative response." Time and careful follow-up will determine the incidence of future diabetes in

\section{$\begin{array}{ll}\text { E.C. } 50^{\circ} & \text { (1)STANDARD - GTT } \\ \text { HT. } 50^{\circ} & \text { (2)CORTISONE-GTT }\end{array}$}
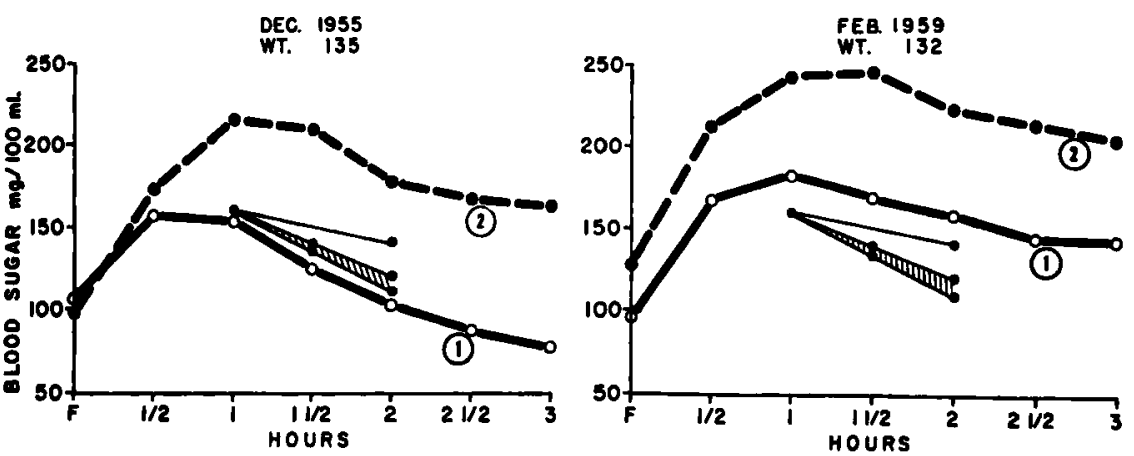

Figure 8. Glucose tolerance tests and cortisone-glucose tolerance tests in a subject with amilial diabetes mellitus (mother).

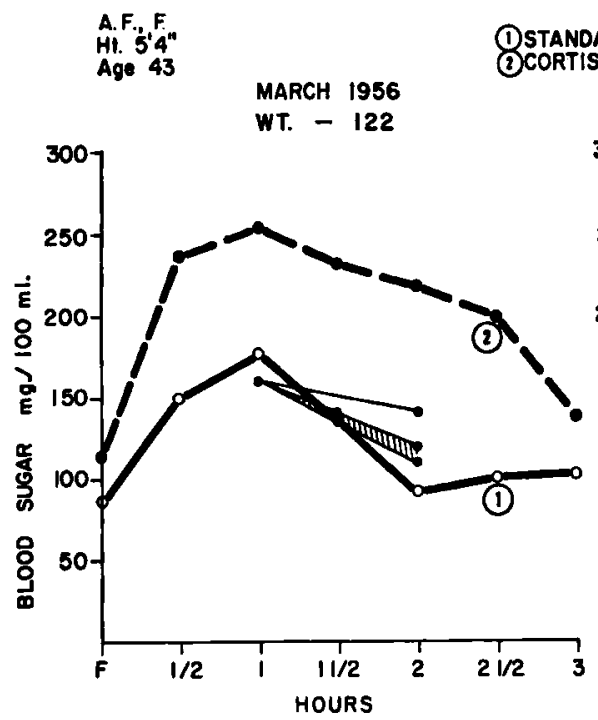

(1)STANDARD - GTT

MARCH 1956

FEB. 1958

WT. -121

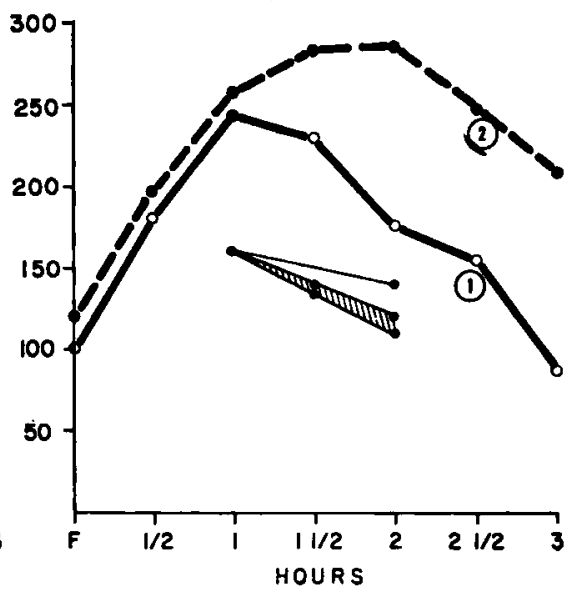

FIGURE 9. Glucose tolerance tests and cortisone-glucose tolerance tests in a subject with familial diabetes mellitus (mother, 5 siblings).

each of the two groups. Such studies have been in progress in 91 nondiabetic relatives of diabetic patients over the last 6 years (TABLE 7).

Of the 91 subjects, 34 had positive responses to the cortisone-glucose tolerance test at the time of the initial tests. Subsequently, 6 (18 per cent) of these 34 subjects have developed diabetes, and another 4 (12 per cent) have probable diabetes. Of the 57 subjects with negative responses to the cortisone- 
glucose tolerance test, only 1 has developed diabetes. In summary, 30 per cent of the positive-response group has developed diabetes or probable diabetes, while only 2 per cent in the negative-response group yielded an abnormal glucose tolerance test at a later date. Thus, the cortisone-glucose tolerance test may prove to be of value as a test for the prediction of future diabetes. Figures 7 and 8 give examples of the progression from a normal glucose tolerance, but abnormal cortisone-glucose tolerance, test to diabetes mellitus in the course of 2 to 4 years. FIGURE 9 illustrates an additional example. Although the initial standard glucose tolerance test could not be classified as one demonstrating diabetes or probable diabetes, it exhibited a mild elevation of the blood sugar level at 1 hour. The cortisone-glucose tolerance test was strongly positive. Two years later the patient was diabetic. This result reemphasizes the possible prognostic importance of an elevated peak blood sugar level.

\section{Summary}

The diagnostic criteria that we employ for the interpretation of the standard oral glucose tolerance test have been reviewed.

Unsuspected diabetes has been found in 19 per cent of 438 close relatives of diabetic patients, while another 4 per cent fell into a category that we have termed "probable diabetes." When these criteria are applied to 127 healthy subjects without a history of familial diabetes or large babies, only 1 glucose tolerance test indicating diabetes and 1 indicating probable diabetes have been found.

Positive responses to the cortisone-glucose tolerance tests have been obtained in 3 per cent of the control group without a family history of diabetes, in 25 per cent of the nondiabetic relatives of diabetic patients, in 88 per cent of patients with probable diabetes, and in 86 per cent of a group of obese diabetic patients whose carbohydrate tolerance had returned to normal after reduction of body weight.

A positive response to the cortisone-glucose tolerance test in nondiabetic individuals can be interpreted as indicating a potentiality or susceptibility for the development of diabetes. Follow-up in 91 nondiabetic relatives of diabetic patients over 1 to 6 years supports this view.

\section{References}

1. Conn, J. W. 1940. Interpretation of glucose tolerance test. Am. J. Med. Sci. 199: 555.

2. FAJANS, S. S. \& J. W. CoNN. 1954. An approach to the prediction of diabetes mellitus by modification of the glucose tolerance test with cortisone. Diabetes. 3: 296 .

3. Moyer, J. H. \& C. R. Womack. 1950. Glucose tolerance: comparison of four types of diagnostic tests in 103 control subjects and 26 patients with diabetes. Am. J. Med. Sci. 219: 161 .

4. Mosenthal, H. O. \& E. BarRy. 1950. Criteria for and interpretation of normal glucose tolerance tests. Ann. Intern. Med. 33: 1175.

5. Seltzer, H. S., S. S. Fajans \& J. W. Conn. 1956. Spontaneous hypoglycemia as an early manifestation of diabetes mellitus. Diabetes. 6: 437.

6. Ackerman, I. P., S. S. Fajans \& J. W. Conn. 1958. The development of diabetes mellitus in patients with nondiabetic glycosuria. Clin. Research. 6: 251.

7. NEWBURGB, L. H. \& J. W. ConN. 1939. A new interpretation of hyperglycemia in obese, middle-aged persons. J. Am. Med. Assoc. 112: 7.

8. Fajans, S. S. \& J. W. CoNN. 1955. Further studies on a test for the "prediction" of diabetes mellitus. Clin. Research Proc. 3: 122.

9. Cons, J. W. 1958. The prediabetic state in man. Diabetes. 7: 347. 